\title{
PROPOLIS SUPPLEMENTATION AND THE CHANGES IN THE OXIDATIVE METABOLISM OF BLOOD PLATELETS EXPOSED TO ELECTROMAGNETIC RADIATION
}

\author{
Gabriela Henrykowska ${ }^{1)}$, Maria Dziedziczak-Buczyńska ${ }^{1)}$, Jacek Buczyński ${ }^{1)}$, Włodzimierz Ziółkowski ${ }^{2)}$, \\ Andrzej Buczyński ${ }^{1)}$ \\ ${ }^{1)}$ Department of Epidemiology and Public Health, Medical University, Łódź, Poland \\ ${ }^{2)}$ University of Computer Sciences and Skills, Łódź, Poland
}

\begin{abstract}
Introduction. Electromagnetic radiation (EMR) that has an effect on living organisms may be a source of oxidative stress. A lack of proper compensation by antioxidant defences on the part of proteins leading to an uncontrolled growth of reactive forms of oxygen, which may give rise to numerous health conditions. Various scientific studies have indicated that propolis has multiple valuable medicinal properties: antibacterial, anti-inflammatory, antioxidant, protective - in relation to liver parenchyma, as well as anti-cancer. Nonetheless, the results of studies concerned with its antioxidant capabilities are not explicit and require further tests and analyses.

Objective. Determination of the effect of propolis supplementation on selected oxidative stress parameters in blood platelets exposed to electromagnetic radiation mitted by LCD monitors.

Material and methods. The material was a suspension containing human blood platelets. A $7 \%$ propolis solution was added to a cellular preparation before an exposure to EMR with a frequency of $1 \mathrm{kHz}$ and an intensity of the electric component of $220 \mathrm{~V} / \mathrm{m}$ (corresponding to sitting a distance of $15 \mathrm{~cm}$ from an LCD screen) for a total of 60 minutes. Before the exposure, as well as immediately following it, the researchers determined the level of activity of superoxide dismutase and malondialdehyde concentration, and evaluated it with regard to the control sample, i.e. material which was not subjected to EMR exposure.

Results. Electromagnetic radiation caused a statistically significant decrease in superoxide dismutase activity as compared with the reference group, irrespective of propolis supplementation. All of the studied groups indicated a minimal increase in the malondialdehyde concentration as compared with its initial values; however, the differences were not statistically significant.

Conclusions. The obtained results allow to conclude that the analysed electromagnetic radiation produced unfavourable changes in the activity of one of the enzymes responsible for antioxidative protection - superoxide dismutase (SOD - 1), and, moreover, a slight intensification in lipid peroxidation, which is expressed by an increase in malondialdehyde concentration (MDA). The supplementation with $7 \%$ propolis solution does not constitute sufficient protection against the negative effect of EMR. It is necessary to conduct further studies as well as determine the behaviour of other antioxidative enzymes. Key words: electromagnetic radiation, LCD screens, propolis, intracellular antioxidant system, blood platelets..
\end{abstract}

\section{ARTICLE INFO}

PolHypRes 2015 Vol. 50 Issue 1 pp. $61-68$

ISSN: $1734-7009$ eISSN: 2084-0535

DOI: $10.1515 / \mathrm{phr}-2015-0006$

Pages: 8 , figures: 2 , tables: 0

page $w w w$ of the periodical: www.phr.net.pl

Publisher

Polish Hyperbaric Medicine and Technology Society

\section{Original article}

Delivery date: $14.12 .2014 \mathrm{r}$

Date of approval for print: $15.01 .2015 r$ 


\section{INTRODUCTION}

Humans have used bee products from the dawn of history. Propolis, also known as bee glue, is a gluey, resinous and thermoplastic material.

The raw material for the production of propolis is brought into a hive in the form of resin drops on the limbs of bees, and next it is chewed by stationary bees, which modifiy its composition with the secretion from the salivary and wax glands, thus increasing its pharmacological effect [1].

The composition of propolis is extremely complex. It contains nearly 300 different chemical substances. The main components include: phenolic compounds - ca. $58 \%$, beeswax - ca. $24 \%$, flavonoids - ca. $6 \%$, essential oils, lipid-wax substances, bioelements, vitamins (A, B2, B6, C, D, E, nicotinic acid, panthothenic acid), proteins, enzymes, amino acids [1,2].

Propolis exhibits numerous pharmaceutical properties, such as antibactieral, antifungal, antivirus, antiinflammatory, hepatoprotective, immunostimulating, anticancer, cytostatic and an antioxidative effect $[3,4,5]$.

Electromagnetic radiation (EMR) has been present in the human environment for many years. As an environmental factor it may have both a positive and negative effect on the human organism, which is why it is a subject of ongoing research.

The EMR that works on living organisms may be a source of oxidative stress [6], the lack of proper compensation of antioxidative protection on the part of proteins leading to an uncontrolled growth of reactive forms of oxygen and may be behind numerous health conditions associated with the activity of free radicals (such as circulatory system diseases, sclerosis, diabetes, tumours) $[7,8]$.

The measures that may protect against the harmful effects induced by free radicals focus on the correct preparation of vegetable matter and thus ultimately one's diet - this should constitute a rich source of nutrients as well as compounds with antioxidant properties and the ability to scavenge free radicals.

The antioxidant properties of propolis have been investigated by numerous authors, nonetheless the results of their research are not explicit $[4,5,9]$. Moreover, there are no findings pointing to mutual interactions between propolis and electromagnetic radiation.

\section{OBJECTIVE}

The aim of the work was to determine the effect of propolis supplementation on selected oxidative stress parameters in the blood platelets exposed to electromagnetic radiation emitted by LCD monitors.

\section{MATERIAL AND METHODS}

The material was a suspension of human blood platelets with the concentration of $10^{-9} / \mathrm{cm}^{3}$. It was obtained through manual apheresis from the blood (whole) of volunteer blood donors, preceded with physical examinations.

Moreover, the collected blood samples were subject to complex laboratory testing. The preparations were transported to a laboratory in a container made from transformer sheet, which shielded the research material from any ambient electromagnetic field.
The material was then subjected to electromagnetic radiation with a frequency of $1 \mathrm{kHz}$, the electric component having an intensity of $220 \mathrm{~V} / \mathrm{m}$ - this corresponding to sitting a distance of $15 \mathrm{~cm}$ from the screen. The exposure time was 60 minutes.

The source of the electromagnetic field was a flat capacitor prepared with the use of two circular copper plates placed over and under a support made from a plastic material.

The electrodes of the capacitor, between which the samples with the research material were placed, were supplied with voltage from an isolation amplifier. Its input was connected to an arbitrary signal generator 8010 manufactured by HAMEG, generating a voltage signal with the flow of the electric component compliant with that of a field emitted by an LCD monitor.

The measurement of intensity of the electric component of the field was performed with a TRACER EF100 electrometer.

The pharmacopeal rotation is performed with ethanolic propolis solutions with the concentrations of $3 \%, 7 \%$ and $10 \%$. The study was carried out with the use of a $7 \%$ ethanolic propolis solution, which was added into the preparation in accordance with the following scheme: Reference group:

- blood cell preparation test groups:

- blood cell preparation + propolis solution,

- blood cell preparation + a 60-minute exposure to EMR

- blood cell preparation + propolis solution + a 60-minute exposure to EMR

Per each $1 \mathrm{~cm}^{3}$ of the blood cell preparation there were $1,365 \mu \mathrm{l}$ of ethanolic propolis solution $(0.079$ $\mathrm{mg}$ propolisu). This quantity was established on the basis of a pharmacopeal propolis solution with the concentration of $7 \%$, which is taken orally in a single dose equal to $7.5 \mathrm{ml}$ per day (i.e.. $58 \mathrm{mg}$ propolis $/ \mathrm{ml}$ ).

It was assumed that following the absorption of the organism the value will be correspond to the volume of 5.5 liters of blood.

Before the exposure, as well as immediately following it, the researchers determined the activity of superoxide dismutase (SOD-1) and malondialdehyde (MDA) concentration and evaluated it in relation to the control sample, i.e. the material which was not subjected to an EMR exposure.

The SOD-1 activity and the MDA concentration were also measured in the group which was not exposed to EMR, but which had had this supplemented with propolis. The measurement was carried out with the use of a CARY 100 BIO spectrophotometer manufactured by VARIAN. Each measurement was performed on 24 samples. All of the obtained results were then collectively subjected to statistical analysis.

\section{RESULTS}

Electromagnetic radiation with an intensity of 1 $\mathrm{kHz}$ and an electric component of $220 \mathrm{~V} / \mathrm{m}$ caused a statistically significant decrease in the activity of superoxide dismutase in the exposed blood platelets as compared with the control group, from the platelet protein value of $x=2400.3$ to $x=1301.73 \mathrm{U} / \mathrm{g}$.

The application of a propolis solution before an exposure to electromagnetic radiation did not have an inhibitory effect on the decrease in the activity of this enzyme. 
What was observed, however, were changes between the group exposed to EMR and the group supplemented with propolis and then exposed to electromagnetic radiation. In the first of them, a decrease in SOD-1 activity of $45.77 \%$ was noted, whereas in the second only by $38.68 \%$ in relation to the control group. (fig. 1).

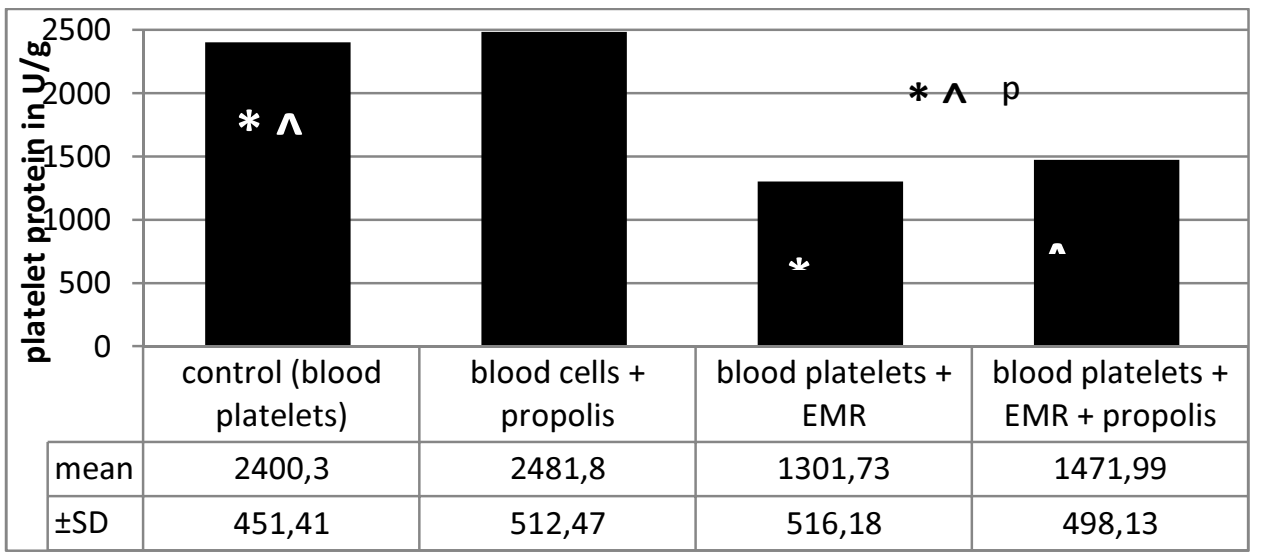

Fig. 1. Enzymatic activity of superoxide dismutase in blood platelets exposed to electromagnetic radiation and propolis.

None of the researched groups showed a statistically significant increase in the concentration of malondialdehyde in relation to the initial values. However the exposure to electromagnetic radiation as well as propolis supplementation induced an increase in MDA concentration.
The highest values of malondialdehyde concentration in relation to initial values were noted in the group supplemented with propolis which was subjected to EMR (fig. 2).

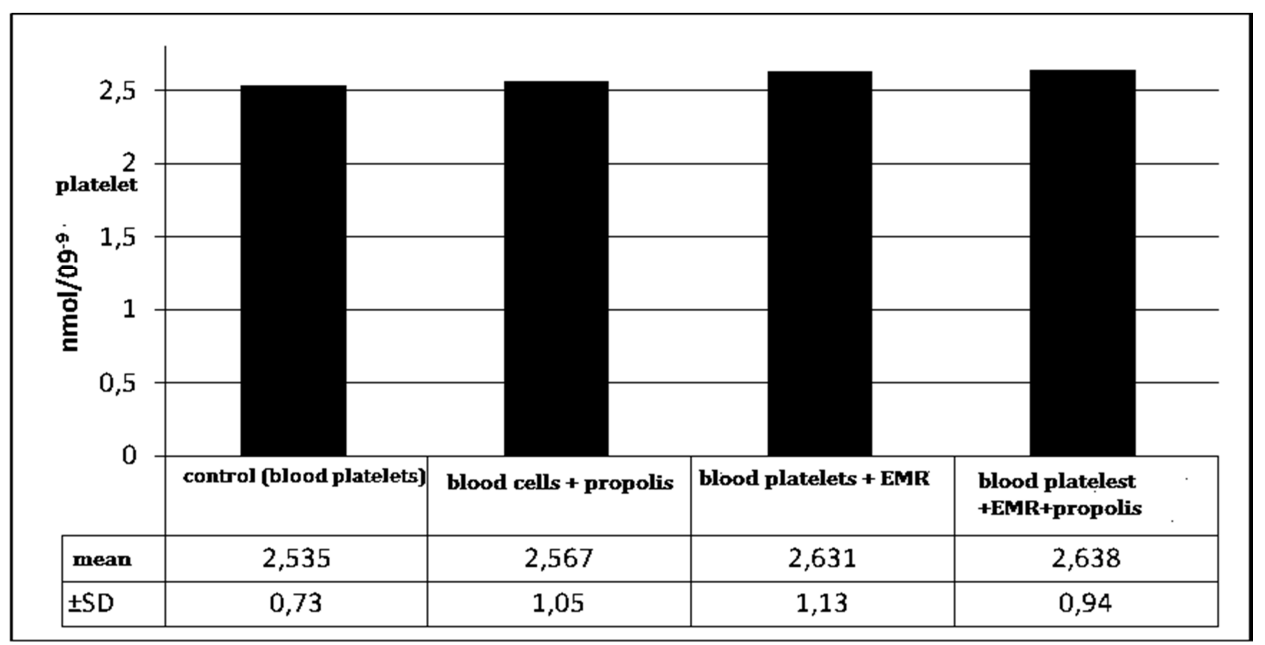

Fig. 2. Malondialdehyde concentration in blood platelets exposed to electromagnetic radiation and propolis.

\section{DisCUSSION}

The dynamic development of analytical sciences has enabled a more accurate determination of the properties and chemical composition of propolis, a natural plant product of honey bees.

Ongoing works are being carried out involving standardisation of the biologically active substances contained in propolis. Its extracts are known for their antibacterial, antivirus, anti-inflammatory and anti-cancer properties $[2,10]$. Moreover, studies have shown that it includes polyphenol substances containing, among other things, flavonoid and cinnamic acid [10].
The antioxidant effect of propolis is due to the content of numerous phenolic compounds. One of them caffeic acid phenylethyl ester (CAPE) is a natural NFkappaB inhibitor with anti-cancer properties $[10,11]$.

A linear relationship has been observed between the total content of polyphenols and flavonoids in the tested propolis samples and its antioxidative effect $[12,13]$.

Other authors report that propolis has the capability of scavanging free radicals in reaction with a stable 1,1-diphenyl-2-picrylhydrazyl radical (DPPH) $[14,15]$. Serra Bonhevi and Ventura Coll proved the activity of propolis in relation to alkyl peroxide, which is 
characterised by its antibacterial effect. Adding propolis to the reaction mixture caused bacterial growth on agar plates [16].

Mika and Tynka noted that an ethanol propolis extract has a bactericidal effect on gram-positive and gram-negative bacteria, both after a 24-hour and a 48hour incubation period at a temperature of $37^{\circ} \mathrm{C}$. It was also shown that propolis in a solid form, not purified, did not manifest such properties [17].

Tests on animals indicated that bee honey, propolis and bee pollen were capable of eliminating from an organism metals that are harmful to health, and in particular heavy metals.

This effect is due mainly to flavonoid compounds occurring in these products which in connection with metals result in combinations which are water soluble (chelates) and thus remove them from an organism [18].

Further research was concerned with the effect of propolis on lipid peroxidation in liver microsomes in rats. It was proven that, depending on the applied dose, propolis inhibited oxidation of fatty acids [19].

Additionally, propolis has an effect on the occurrence of free radicals. Research indicated its inhibitory effect on xanthine oxidase which oxidises xanthines to uric acid [20] causing the occurrence of superoxide anion radicals.

Own studies allowed to observe a minimal increase in malondialdehyde concentration, which is a marker of cell membrane peroxidation, in the blood platelets exposed to electromagnetic radiation. Adding propolis to the research material resulted in a further increase in MDA concentration.

Lewicka and others made an observation that under the electromagnetic radiation generated by LCD monitors, an uncontrolled process consisting in the generation of reactive forms of oxygen occurs in blood platelets which is accompanied with a simultaneous decrease in the activity of superoxide dismutase [21].

Koyu and co-authors indicated that caffeic acid phenylethyl ester (CAPE) induced changes in the livers of rats exposed to electromagnetic radiation with the intensity of $900 \mathrm{MHz}$ by strengthening the antioxidative defence manifested in a reduction of reactive forms of oxygen and an increase in SOD-1 activity [22].

In the authors' own research, EMR intensively reduced the enzymatic activity of superoxide dismutase in blood platelets. Adding propolis resulted in a slight increase in the activity of the antioxidative system; however, it did not prevent the induced free radical changes.

Numerous studies have proven that changes caused by electromagnetic radiation at the cellular level may lead to certain health conditions in an organism as a whole. The systems which are most susceptible to the impact of this factor are: the circulatory system, the nervous system and the endocrine and lymphatic systems.

Thus, it seems important that further research is conducted with the purpose of seeking efficient antioxidants which would support the human organism.

\section{Conclusions}

The obtained results allow to confirm that the analysed electromagnetic radiation causes adverse changes in the activity of one of the antioxidative defence enzymes - superoxide dismutase.

Moreover, the study indicated a slight intensification in lipid peroxidation, which is expressed in an increased concentration of malondialdehyde. Nonetheless, no statistically significant correlations were noted between the obtained values.

Supplementation with a $7 \%$ propolis solution does not provide sufficient protection against the negative effect of electromagnetic radiation emitted from the distance of $15 \mathrm{~cm}$ by screen monitors.

It is necessary to conduct further studies as well as determine the behaviour of other antioxidative enzymes.

\section{BIBLIOGRAPHY}

1. Tichonov A. I. and others; Theory and practice in the production of medicinal propolis preparations. Apipol-Farma, Myślenice, 2004.

2. Kędzia B., Hołoderna-Kędzia E.: Chemical composition of propolis in the light of the hitherto executed research. Herba Pol., 1991, XXXVIII, 2, 95-110.

Kwakman PHS. and others: How honey kills bacteria, The FASEB Journal, 2010, 24, 2576-2582.

4. Castaldo S., Capasso F.: Propolis, an old remedy used in modern medicine. Fitoterapia, 2002, 73, Suppl.1, S1-S6

5. Ozguner $\mathrm{F}$, Bardak $\mathrm{Y}$, Comlekci S. Protective effects of melatonin and caffeic acid phenethyl ester against retinal oxidative stress in long-term use of mobile phone: a comparative study. Mol Cell Biochem. 2006 Jan;282(1-2):83-8.

6. Balci M, Namuslu M, Devrim E, Durak I. Effects of computer monitor-emitted radiation on oxidant/antioxidant balance in cornea and lens from rats. Molecular Vision 2009; 15: 2521-2525.

7. Canseven A.G., Coskun S., Seyhan N., Effects of various extremely low frequency magnetic fields on the free radical processes, natural antioxidant system and respiratory burst system activities in the heart and liver tissues. Indian. J. Biochem. Biophys. 2008, Oct. 45(5): 326-31.

8. Röösli M, Egger M, Pfluger D, Minder C. Cardiovascular mortality and exposure to extremely low frequency magnetic fields: a cohort study of Swiss railway workers. Environ. Health. 2008; Jul 1;7: 35.

9. Bankowa V.: Chemical diversity of propolis and the problem of standardization. J Etnopharmacol., 2005, 100, 114-117.

10. Nakajima Y., Shimazawa M., Mishima S., Hara H. Water extract of propolis and its main constituents, caffeoylquinic acid derivatives, exert neuroprotective effects via antioxidant actions. Life Sci. 2007; 80: 370-377.

11. Demestre $M$ and others CAPE (caffeic acid phenethyl ester)-based propolis extract (Bio 30 ) suppresses the growth of human neurofibromatosis (NF) tumor xenografts in mice. Phytother Res 2009; 23: 226-230.

12. Kumazawa S., Hamasaka T., Nakayama T.: Antioxidant activity of propolis of various geographic origins. Food Chem, 2004, 84, 329-339.

13. Li-Chang Lu, Yue-Wen Chen, Cheng-Chun Chou. Antibacterial and DPPH free radical scavenging activities of the ethanol extract of propolis collected in Taiwan. J. Food Drug Anal., 2003, Vol. 11, no 4, 277-282 J.

14. Shimizu K., Ashida H., Matsuura Y., Kanazawa K.: Antioxidative bioavailability of artepilin C in Brazilian propolis. Arch. Biochem. Biophy. 2004, 424, 181-188.

15. Capucho C, Sette R, de Souza Predes F, de Castro Monteiro J, Pigoso AA, Barbieri R, Dolder MA, Severi-Aguiar GD. Green Brazilian propolis effects on sperm count and epididymis morphology and oxidative stress. Food Chem Toxicol. 2012 Nov;50(11):3956-62.

16. Serra Bonvehi J., Ventura Coll F.: Study on Propolis Quality from China and Uruguay. Z. Naturforsch. 2000, 55c, 778-784 
17. Mika B. Tynka B. The comparison of bactericidal effect of various types of honey and propolis on gram-positive and gram-negative bacteria. Internet source: https://kbs.ise.polsl.pl/sknb/wp-content/.../Mika_Tynka-artykuł.pdf.

18. Kędzia B, Hołderna-Kędzia $E$. The elimination of harmful metals from an organism with the use of bee products. Herba polonica, 2009, 55,1: 95108.

19. Shinohara R., Ohta Y., Hayashi T., Ikeno T.: Evaluation of antilipid peroxidative action of propolis ethanol extract. Phytother. Res., 2002, 16, 340-347.

20. Russo A., Longo R., Vanella A.: Antioxidant activity of propolis: role of caffeic acid phenethyl ester and galangin. Fitoterapia, 2002, 73, Suppl 1, 21- 29

21. Lewicka M. and others Changes in the activity of superoxide dismutase in blood platelets exposed to electromagnetic radiation emitted by LCD screens - in vitro studies. Kwart. Ortop. 2011, 1, 31-37.

22. Koyu A. Ozguner F, Yilmaz H. The protective effect of caffeic acid phenethyl ester (CAPE) on oxidative stress in rat liver exposed to the 900 $\mathrm{MHz}$ electromagnetic field. Toxicol Ind Health. 2009 Jul;25(6):429-34.

23. Buczyński A., Pacholski K., Dziedziczak - Buczyńska and others; Alterations in the generation of free radicals in blood platelets exposed to electromagnetic radiation emitted by screen monitors; Polish Hyperbaric Research 2010; 1 (30).

dr n. med. Gabriela Henrykowska

Zakład Epidemiologii i Zdrowia Publicznego,

Uniwersytet Medyczny w Łodzi

gabriela.henrykowska@umed.lodz.pl 